\title{
Modern sonology and the bedside practitioner: evolution of ultrasound from curious novelty to essential clinical tool
}

\author{
S. P. Stawicki • D. P. Bahner
}

Received: 21 August 2014 / Accepted: 20 October 2014 / Published online: 4 November 2014

(C) Springer-Verlag Berlin Heidelberg 2014

Sonography-based clinical assessment continues to gain traction as an essential clinical tool throughout the world $[1,2]$. In that context, it is critical to recognize the truly global effort to introduce, popularize, and further advance the use of sonography in everyday clinical practice across the planet $[1,3,4]$. Sonology, or the science of performing bedside ultrasound exam and the associated clinical interpretation, is now an established scientific discipline that empowers the bedside practitioner to not only acquire relevant anatomic images, but to analyze their meaning, and to determine the clinical course of action accordingly [5, 6]. More importantly, due to sonographic equipment miniaturization, sonologists are no longer restricted to the office or hospital settings, but can assist patients in a variety of prehospital, geographically remote and austere environments [7-9].

As portable (i.e., mobile platform-based and truly handheld) ultrasound units become common place [10], nonradiology practitioners stand to gain true opportunity to glimpse into the inner workings of the body and turn that ability to practical, often life-saving, interventions [11, 12]. The true impact of sonology is easily appreciated by performing a simple internet search using the very phrase "bedside sonography", with 2,061 results on PubMed and 17,900 results on Google ${ }^{\mathrm{TM}}$ Scholar (search performed on June 26, 2014).

\footnotetext{
S. P. Stawicki $(\square)$

Department of Research and Innovation, St Luke's University Health Network, Bethlehem, PA 18015, USA

e-mail: stawicki.ace@gmail.com

D. P. Bahner

Department of Emergency Medicine, The Ohio State University

College of Medicine, Columbus, $\mathrm{OH} 43210$, USA
}

When one uses versatility as the benchmark, the power of sonography becomes truly obvious as the number of its potential applications and disciplines involved is examined. For example, sonologists and proceduralists can claim substantial contributions in the areas of central [13] and peripheral [14] venous access, disaster triage [15], musculo-skeletal diagnosis and treatment [16, 17], vascular diagnosis [18], intravascular volume status assessment [19], cardiovascular assessment [20, 21], tracheal airway placement verification [2], ophthalmologic and neurologic applications [22-25], diagnosis of cholecystitis [26, 27], appendicitis [28], and abdominal solid organ abnormalities [29-32], obstetric and gynecologic applications [33, 34], and percutaneous drainage of fluid collections [35, 36], among many other clinical uses [37-41].

Principal aim of the next two special issues of EJTES is to highlight the progress of sonology as a discipline, focusing on the procedural and emergency applications. One of the key concepts central to the new sonology-based practice is the "I-AIM" paradigm [42]. Here, the independently functioning practitioner operates based on the premises of "indication, acquisition, interpretation, and medical decision-making". More specifically, each sonographic exam should carry a specific indication, along with a pretest probability. There has to be an orderly image acquisition procedure, followed by an established interpretation of the acquired data. Finally, the findings are translated into the paradigm of medical decision-making, where a consideration is given to perform specific clinical interventions, and/or altering the clinical course of action, based on said results [7, 43].

The merging of miniaturization, portability and a diverse need for diagnostic certainty at the bedside has led to a boom in ultrasound in medical education [44-46]. As more practitioners integrate ultrasound into their clinical 
practice, the question becomes whether it is used simply as an aid to the physical exam or, in a more advanced context, as a diagnostic procedure with saved images and a generated report [47]. This is the next part of this transformational journey as ultrasound is taught at the earliest stages in medical school and residency, focusing on the scientific foundations behind the practical way sonology is utilized and applied in a variety of clinical scenarios.

The needs of the patient can be answered with knowledge of acoustics and artifacts as well as the awareness of how ultrasound can detect fluid collections or air in various spaces in the human body [48-54]. The physiologic, anatomic, and pathologic findings detected with ultrasound can help the clinician at the bedside put the clinical context to what he or she is "seeing" on the ultrasound monitor. All the required skills can be taught, students and residents can learn, yet ultrasound has still not achieved its full potential within the landscape of modern medicine. How do we go further? How do we truly integrate ultrasound into the way we diagnose, prognosticate, and treat our patients?

Well, the very next step is for health care decision makers to implement a more ultrasound-centric practical change in the care for patients. Many authors decry the dangers of ionizing radiation associated with much overused computed tomography [55-58] as well as the escalating costs of health care [59]. Consequently, the authors' hope is that ultrasound can be operationalized into modern medicine on a more systematic and algorithmic basis to remedy these systemic problems, among many others. Ultrasound use in screening and coordinating care at both modern medical centers and in austere environments opens up new avenues for creative clinicians to broach the chasm from bench to bedside. How can ultrasound better help the patient?

Smart technology is all about using existing capabilities and innovating upon those in incremental fashion. The use of ultrasonic waves to produce images of the human body has revolutionized the critical care of the ill or injured patients, as well as the field of bedside procedures. As our collective knowledge advances, the technological improvements will lead to better devices and superior image quality [60-62]. It is up to the sonologist to create static and/ or moving images that tell a medical story. The ultrasound can help the practitioner find fluid in a number of potential spaces like interstitium, or along tissue planes around the retina, or perhaps in Morison's pouch or the Paracolic gutters. Finding and draining fluid collections with ultrasound can help the provider make decisions, facilitating "yes/no" answers to dichotomous questions. As the practitioner uses the tools to inform a decision, a focused ultrasound application helps answer specific questions. The impact of sonography is profound, its possibilities vast, and the number of clinical stories to be told is truly limitless!
The future of ultrasound is very bright but we must not forget the late adopters and the skeptics. The ultrasound technology is, of course, operator dependent and can be difficult to use, misleading at times, and prone to misinterpretations by the novice user. Consequently, early and comprehensive sonology education is a must, with emphasis on focused ultrasound applications and pertinent skillbased practice early in a career. As time passes and reach of ultrasonography expands, practitioners will likely find an expanding array of bedside sonography uses as they strive to help patients and provide safer, reliable, and efficient care. Sonology is the practice of using ultrasound at the bedside to assist the practitioner in their medical decisionmaking. The next two focus issues of the European Journal of Trauma and Emergency Surgery will provide a comprehensive insight into the modern face of this exciting and growing field.

Conflict of interest Stanislaw P. Stawicki MD FACS and David P. Bahner MD RDMS declare that they have no conflict of interest related to this work.

Compliance with ethical requirements This work is in compliance with ethical requirements.

\section{References}

1. Zago M. Time for a comprehensive ultrasound-enhanced trauma management. Eur J Trauma Emerg Surg. 2009;35(4):339-40.

2. Bahner DP, et al. What's new in critical illness and injury science? The challenge of verifying tracheal airway placement: solving the puzzle one piece at a time. Int J Crit Illn Inj Sci. 2013;3(2):105-7.

3. Han JK. Another step toward the global ultrasound community. Ultrasonography. 2014;33(1):2.

4. Via G, et al. Point of care ultrasound for sepsis management in resource-limited settings: time for a new paradigm for global health care. Intensive Care Med. 2012;38(8):1405-7 (Author reply 1408-9).

5. Coffin C, et al. The ultrasound practitioner: response to the SDMS for the development of a middle care provider in ultrasound imaging. (2002) June 27, 2014. http://www.sdms.org/pdf/jdmsup.pdf.

6. Stawicki SP. Sonowiki: Sonology. (2014) June 28, 2014. http://w ww.sonowiki.com/wiki/mediawiki-1.11.1/index.php/Sonology.

7. Blaivas $M$, et al. Change in differential diagnosis and patient management with the use of portable ultrasound in a remote setting. Wilderness Environ Med. 2005;16(1):38-41.

8. Melanson SW, et al. Aeromedical trauma sonography by flight crews with a miniature ultrasound unit. Prehosp Emerg Care. 2001;5(4):399-402.

9. Ruesseler M, et al. Prehospital and emergency department ultrasound in blunt abdominal trauma. Eur J Trauma Emerg Surg. 2009;35:341-6.

10. Kirkpatrick AW, et al. Rapid diagnosis of an ulnar fracture with portable hand-held ultrasound. Mil Med. 2003;168(4):312-3.

11. Menaker J, et al. Ultrasound-diagnosed cardiac tamponade after blunt abdominal trauma-treated with emergent thoracotomy. J Emerg Med. 2007;32(1):99-103.

12. Rodgerson JD, et al. Emergency department right upper quadrant ultrasound is associated with a reduced time to diagnosis 
and treatment of ruptured ectopic pregnancies. Acad Emerg Med. 2001;8(4):331-6.

13. Fry WR, Clagett GC, O'Rourke PT. Ultrasound-guided central venous access. Arch Surg. 1999;134(7):738-40 (Discussion 741).

14. Blackshaw R, Peat W, Youngs P. Use of ultrasound to obtain peripheral venous access. Int J Obstet Anesth. 2006;15(2):174-5.

15. Stawicki SP, et al. Portable ultrasonography in mass casualty incidents: the caveat examination. World J Orthop. 2010;1(1):10-9.

16. Royall NA, et al. Ultrasound-assisted musculoskeletal procedures: a practical overview of current literature. World J Orthop. 2011;2(7):57-66.

17. Al-Kadi AS, et al. Resuscitative long-bone sonography for the clinician: usefulness and pitfalls of focused clinical ultrasound to detect long-bone fractures during trauma resuscitation. Eur $\mathbf{J}$ Trauma Emerg Surg. 2009;35(4):357-63.

18. Dippel DW, et al. The diagnostic value of colour duplex ultrasound for symptomatic carotid stenosis in clinical practice. Neuroradiology. 1999;41(1):1-8.

19. Stawicki SP, et al. Prospective evaluation of intravascular volume status in critically ill patients: does inferior vena cava collapsibility correlate with central venous pressure? J Trauma Acute Care Surg. 2014;76(4):956-63 (Discussion 963-4).

20. Shoenberger JM, Massopust K, Henderson SO. The use of bedside ultrasound in cardiac arrest. Cal J Emerg Med. 2007;8(2):47-50.

21. Niendorff DF, et al. Rapid cardiac ultrasound of inpatients suffering PEA arrest performed by nonexpert sonographers. Resuscitation. 2005;67(1):81-7.

22. Naggar CZ, McDonald DG. Ultrasound in medical diagnosis. Part II. Neurologic and abdominal applications. Heart Lung. 1977;6(5):829-37.

23. Whelan CA, Passalaqua AM, Braunstein P. Nuclear medicine and ultrasound in the evaluation of neurologic diseases. Semin Nucl Med. 1975;5(4):419-31.

24. Garcia JP Jr, et al. Surface rendering of 3D ultrasound images in ophthalmology. Ophthalmic Surg Lasers Imaging. 2006;37(4):347-51.

25. Fledelius HC. Ultrasound in ophthalmology. Ultrasound Med Biol. 1997;23(3):365-75.

26. Nagdev A, Ward J. Bedside ultrasound diagnosis of acalculous cholecystitis from epstein-barr virus. West J Emerg Med. 2011;12(4):481-364

27. Becker BA, et al. Emergency biliary sonography: utility of common bile duct measurement in the diagnosis of cholecystitis and choledocholithiasis. J Emerg Med. 2014;46(1):54-60.

28. Sivitz AB, Cohen SG, Tejani C. Evaluation of acute appendicitis by pediatric emergency physician sonography. Ann Emerg Med. 2014;64(4):358-364

29. Riddell J, et al. Sensitivity of emergency bedside ultrasound to detect hydronephrosis in patients with computed tomographyproven stones. West J Emerg Med. 2014;15(1):96-100.

30. Trinquart L, et al. A hand-held ultrasound machine vs conventional ultrasound machine in the bedside assessment of post-liver transplant patients. Eur Radiol. 2009;19(10):2441-7.

31. Riley TR 3rd, Mendoza A, Bruno MA. Bedside ultrasound can predict nonalcoholic fatty liver disease in the hands of clinicians using a prototype image. Dig Dis Sci. 2006;51(5):982-5.

32. Iyanaga M, Watts $S$, Kasai T. A patient with splenic artery aneurysm rupture and the importance of rapid sonography in the ED. Emerg Med Int. 2010;2010:893606.

33. Glazebrook R, Manahan D, Chater AB. Evaluation of an ultrasound program (intermediate obstetric and emergency medicine) for Australian rural and remote doctors. Aust J Rural Health. 2005;13(5):295-9.

34. Estroff JA. Emergency obstetric and gynecologic ultrasound. Radiol Clin North Am. 1997;35(4):921-57.
35. Flament JB, et al. Ultrasound-guided percutaneous drainage of intraperitoneal fluid collections. An experience of a surgical team with 205 patients. Chirurgie. 1991;117(4):298-310 (Discussion 310-1).

36. Ng J, Chua GT, Ng A. Ultrasound guided drainage of pleural fluid. Indiana Med. 1989;82(4):282-4.

37. El Sayed MJ, Zaghrini E. Prehospital emergency ultrasound: a review of current clinical applications, challenges, and future implications. Emerg Med Int. 2013;2013:531674.

38. Hartman $\mathrm{C}$, et al. Bone quantitative ultrasound and nutritional status in severely handicapped institutionalized children and adolescents. Clin Nutr. 2004;23(1):89-98.

39. Badve M, et al. Ultrasound guided epidural analgesia for labor in a patient with an intrathecal baclofen pump. Int J Obstet Anesth. 2011;20(4):370-2.

40. Kube E, Stawicki SP, Bahner DP. Ultrasound in the diagnosis of Fournier's gangrene. Int J Crit Illn Inj Sci. 2012;2(2):104-6.

41. Stawicki SP, et al. Incidental findings on intensivist bedside ultrasonographic (INBU) examinations: why should we care? OPUS 12 Sci. 2008;2(3):11-4.

42. Bahner DP, Hughes D, Royall NA. I-AIM: a novel model for teaching and performing focused sonography. J Ultrasound Med. 2012;31(2):295-300.

43. Breitkreutz R, et al. Does the integration of personalized ultrasound change patient management in critical care medicine? Observational trials. Emerg Med Int. 2013;2013:946059.

44. Hoppmann RA, et al. An integrated ultrasound curriculum (iUSC) for medical students: 4-year experience. Crit Ultrasound J. 2011;3:1-12.

45. Rao S, et al. A pilot study of comprehensive ultrasound education at the Wayne State University School of Medicine: a pioneer year review. J Ultrasound Med. 2008;27(5):745-9.

46. Bahner DP, Royall NA. Advanced ultrasound training for fourthyear medical students: a novel training program at the Ohio State University College of Medicine. Acad Med. 2013;88(2):206-13.

47. Greenbaum LD, et al. Proceedings of the compact ultrasound conference sponsored by the American Institute of ultrasound in medicine. J Ultrasound Med. 2004;23(10):1249-54.

48. Jah A, et al. Endoscopic ultrasound-guided drainage of an abdominal fluid collection following Whipple's resection. World J Gastroenterol. 2008;14(44):6867-8.

49. Coltrera MD. Ultrasound physics in a nutshell. Otolaryngol Clin North Am. 2010;43(6):1149-59.

50. Smith RP. Basic physics of ultrasound. Clin Obstet Gynecol. 1977;20(2):231-41.

51. Buddemeyer EU. The physics of diagnostic ultrasound. Radiol Clin North Am. 1975;13(3):391-402.

52. Carlsen EN. Ultrasound physics for the physician. A brief review. J Clin Ultrasound. 1975;3(1):69-75.

53. Chen HJ, et al. Ultrasound in peripheral pulmonary air-fluid lesions. Color doppler imaging as an aid in differentiating empyema and abscess. Chest. 2009;135(6):1426-32.

54. Kline JP, et al. Detection of pneumothorax with ultrasound. AANA J. 2013;81(4):265-71.

55. Owlia M, et al. Head CT scan overuse in frequently admitted medical patients. Am J Med. 2014;127(5):406-10.

56. McCauley TR. Radiation risk of screening CT. AJR Am J Roentgenol. 2003;180(2):540 (Author reply 540-1).

57. Andronikou S, Fink AM. Radiation risk in paediatric CT. S Afr Med J. 2002;92(7):516.

58. Sierzenski PR, et al. Applications of justification and optimization in medical imaging: examples of clinical guidance for computed tomography use in emergency medicine. J Am Coll Radiol. 2014;11(1):36-44.

59. Tang S, Tao J, Bekedam H. Controlling cost escalation of healthcare: making universal health coverage sustainable in China. BMC Public Health. 2012;12(Suppl 1):S8. 
60. Soetanto K. Recent progress of the medical ultrasound contrast imaging technology. Nihon Rinsho. 1998;56(4):854-9.

61. Xiaoping L, Leizhen Z. Advances of high intensity focused ultrasound (HIFU) for pancreatic cancer. Int $\mathrm{J}$ Hyperthermia. 2013;29(7):678-82.
62. Frederiksen CA, Juhl-Olsen P, Sloth E. Advances in imaging: ultrasound in every physician's pocket. Expert Opin Med Diagn. 2012;6(3):167-70. 